\title{
CAPACITY BUILDING STRATEGY IN SAMARINDA ROAD CLINIC
}

\section{STRATEGI PENGUATAN KAPASITAS (CAPACITY BUILDING) DI KLINIK JALANAN SAMARINDA}

\author{
Syamsul Anwar ${ }^{1}$, Inda Fitriyarini ${ }^{2}$ \\ Universitas Mulawarman, Indonesia
}

Email Correspondence: syamsul.trunbull@gmail.com

\begin{abstract}
:
This study aims to identify and describe 3 (three) aspects of the capacity-building strategy of street children at the Samarinda Street Clinic, namely; Rehabilitation Aspects, Motivational Aspects, and Study Aspects. This study uses an observational approach. Before going down to the field, researchers did not bring or use any theory. The research location is in the Secretariat of the Street Clinic which is located at Jalan K.H. Agus Salim Gang 2, Kota Samarinda, and at the intersection of Jalan Basuki Rahmat traffic signs, Lembuswana Mall traffic sign intersection, Jalan Pangeran Antasari traffic sign intersection, and Sempaja traffic sign intersection. Sources of data come from primary data sources (key informants), namely Haerdy Pratama Wijaya, CEO of Samarinda Street Clinic, and secondary data from the literature. The data collection techniques used participant observation, in-depth interviews, and documentation. The results of this study indicate that 3 aspects of the capacity building strategy at the Samarinda Street Clinic are; aspects of rehabilitation, aspects of motivation, and aspects of studies that have been applied so far can rehabilitate some of the street children who have been addicted to gluing for a long time so that they don't cling anymore, and with the study aspect it can reduce the illiteracy rate of the street children being coached.
\end{abstract}

Keywords: Capacity Building, Strategy, Street Children

\begin{abstract}
ABSTRAK:
Penelitian ini bertujuan untuk mengetahui dan mendeskripsikan 3 (tiga) aspek strategi penguatan kapasitas (capacity building) anak jalanan di Klinik Jalanan Samarinda yaitu; Aspek Rehabilitasi, Aspek Motivasi, dan Aspek Studi. Penelitian ini menggunakan pendekatan observasi. Sebelum turun kelapangan, peneliti tidak membawa atau menggunakan teori apapun. Lokasi penelitian di sekertariat Klinik Jalanan yang beralamat di Jalan K.H. Agus Salim Gang 2, Kota Samarinda dan di persimpangan rambu lalu lintas Jalan Basuki Rahmat, persimpangan rambu lalu lintas Mall Lembuswana, persimpangan rambu lalu lintas Jalan Pangeran Antasari dan persimpangan rambu lalu lintas Sempaja. Sumber data berasal dari sumber data primer (informan kunci) yaitu Haerdy Pratama Wijaya, CEO Klinik Jalanan Samarinda dan data sekunder yaitu dari kepustakaan. Teknik pengumpulan data menggungakan teknik participant observation, wawancara mendalam dan dokumentasi. Hasil penelitian ini menunjukkan bahwa 3 aspek strategi penguatan kapasitas (capacity building) di Klinik Jalanan Samarinda yaitu ; aspek rehabilitasi, aspek motivasi, dan aspek studi yang diterapkan selama ini mampu melakukan rehabilitasi kepada sebagian anak jalanan yang telah lama kecanduan ngelem sehingga tidak ngelem lagi, dan dengan adanya aspek studi dapat menekan angka buta huruf anak jalanan yang dibina.
\end{abstract}

\section{Kata Kunci: Anak Jalanan, Penguatan Kapasitas, Strategi}

\begin{tabular}{l|l|l} 
Article Info & & \\
\hline Received & $:$ & July 2020 \\
\hline Accepted & $:$ & July 2020 \\
Published & $:$ & July 2020 \\
DOI & $:$ & https://doi.org/10.30872/psd.v1i2.18 \\
\hline
\end{tabular}

Copyright and License

Authors retain copyright and grant the journal right of first publication with the work simultaneously licensed under a Creative Commons Attribution 4.0 International License that allows others to share the work with an acknowledgment of the work's authorship and initial publication in this journal. 


\section{PENDAHULUAN}

Anak-anak usia di bawah 16 tahun seharusnya tidak berada di jalanan. Mereka seharusnya masih mendapatkan perlindungan, kasih sayang keluarga, memiliki kesempatan seluas-luasnya untuk bermain, mengembangkan bakat dan kompetensi berpikir. Berdasarkan konvensi hak anak PBB tahun 1989, ada 10 hak yang harus diberikan untuk anak yaitu hak untuk bermain, hak untuk mendapatkan pendidikan, hak untuk mendapatkan perlindungan, hak untuk mendapatkan nama (identitas), hak untuk mendapatkan status kebangsaan, hak untuk mendapatkan makanan, hak untuk mendapatkan akses kesehatan, hak untuk mendapatkan rekreasi, hak untuk mendapatkan kesamaan, hak untuk memiliki peran dalam pembangunan. Dalam UU Nomor 35 Tahun 2014 pasal 48 menyebutkan Pemerintah dan Pemerintah Daerah wajib menyelenggarakan pendidikan dasar minimal 9 (sembilan) tahun untuk semua anak. Artinya bahwa dalam hal mendapat pendidikan dasar, anak-anak menjadi tanggung jawab pemerintah dan pemerintah daerah mulai dari SD hingga SMP.

Namun kenyataannya masih banyak anak-anak hidup di jalanan. Di tahun 2002, berdasarkan hasil Susenas yang diselenggarakan oleh BPS \& Pusdatin Kementrial Sosial tercatat sebanyak 94,674 anak jalanan di Indonesia. Terjadi peningkatan 64\% anak jalanan dari 2002 - 2008 atau rata-rata sekitar 10.6\% per tahun peningkatannya. Menggunakan asumsi terjadi peningkatan $10.6 \%$ per tahun untuk angka anak jalanan, maka di akhir 2015 diperkirakan terdapat tiga ratus ribu anak jalanan di Indonesia. Data terakhir (2008) yang dikeluarkan oleh Badan Pusat Statistik (BPS) menyebutkan bahwa anak jalanan Indonesia berjumlah 154,861 jiwa, dimana hampir separuhnya berada di Jakarta, dan sisanya menyebar di kota besar lainnya seperti Medan, Palembang, Batam, Serang, Bandung, Jogja, Surabaya, Malang, Semarang, dan Makassar.

Di Samarinda hampir setiap hari di beberapa persimpangan lampu merah selalu ada anak-anak jalanan. Dinas Sosial Kota Samarinda menyebutkan anak- anak jalanan hampir setiap hari selalu ada di persimpangan rambu lalu lintas P. Antasari, persimpangan rambu lalu lintas Jalan Basuki Rahmat, persimpangan rambu lalu lintas Mall Lembuswana dan persimpangan rambu lalu lintas Sempaja. Dalam melihat problema anak jalanan pemerintah kota masih memakai paradigma lama. Anak-anak jalanan dianggap sebagai ,aib/penyakit/masalah ${ }^{\text {ee }}$ yang merusak pemandangan kota. Sehingga cara-cara penanganan yang dipilih masih bersifat represif dan temporer. Anak jalanan sering kali dirazia oleh Satuan Polisi Pamong Praja Kota Samarinda namun mereka kembali lagi. Terakhir kali razia anak jalanan dilakukan pada tahun 2014. Dari data, dilihat ada sebanyak 18 anak jalanan berjenis kelamin perempuan dan 45 anak jalanan berjenis kelamin laki- laki. Anak-anak jalanan yang tertangkap pada saat dirazia, kemudian di identifikasi latar belakang diri dan keluarganya. Bagi anak jalanan yang tidak punya orang tua dan tempat tinggal dititipkan di panti-panti asuhan swasta untuk dibina dan di sekolahkan. Sebagian besar dari mereka yang sering terjaring razia bertempat tinggal di Kota Samarinda. (Sumber Dinas Sosial Kota Samarinda).

Cara yang dilakukan oleh Dinas Sosial dengan mengandalkan Satpol PP tidak pernah berhasil menuntaskan problema anak jalanan. Terbukti dari tahun ke tahun jumlah anak jalanan terus meningkat dan bahkan mereka yang pernah atau sering terkena razia masih terus kembali ke jalanan. Di saat pihak pemerintah kota menggunakan cara-cara represif dalam menangani problema anak jalanan, ada beberapa kelompok masyarakat yang memiliki inisiatif membangun cara atau model yang lain untuk mengatasinya. Kelompokkelompok masyarakat yang menangani anak jalanan di Samarinda ada Yayasan Borneo, Yayasan Lentera Mahakam dan Klinik Jalanan Samarinda. Yayasan Borneo dan Yayasan Lentera Mahakam eksistensinya dalam menangani problema anak jalanan masih belum terlihat hingga sekarang. Sedangkan Klinik Jalanan Samarinda adalah poineer model baru yang berbentuk komunitas. Klinik Jalanan adalah komunitas pertama di Kota Samarinda yang menaruh perhatian terhadap problema anak jalanan khususnya pada anak-anak jalanan pecandu lem. Sekilas, model penanganan anak jalanan yang dilakukan pada Klinik Jalanan berbeda dengan model-model penanganan anak jalanan yang dipahami oleh pemerintah ataupun masyarakat pada umumnya. Klinik Jalanan tidak melihat anak-anak jalanan sebagai „aib/penyakit/masalahe tetapi melihat anak-anak jalanan sebagai anak-anak yang layak dan harus mendapatkan perlindungan dan kasih sayang.

Keunikan Klinik Jalanan Samarinda dibandingkan dengan beberapa yayasan lainnya yang menangani problema anak jalanan terlihat dalam kegiatan pembinaan serta keseriusan mereka menangani problema anak jalanan. Klinik Jalanan lebih banyak terlihat kegiatannya dibandingkan yayasan-yayasan yang menangani anak jalanan ataupun pemerintah Kota Samarinda melalui Dinas Sosial. Terlihat pada hari selasa, rabu dan jum eeat dalam setiap minggu klinik ini rutin melakukan pembinaan bersama anak-anak jalanan. Uniknya, Klinik Jalanan melakukan pembinaan hanya pada malam hari di beberapa titik rambu lalu lintas tempat anak jalanan biasa bekerja.

Komunitas Klinik Jalanan Samarinda didirikan oleh Heardy Pratama Wijaya mantan persiden Badan Eksekutif Mahasiswa (BEM) Universitas Mulawarman periode 2013-2014 dengan dibantu oleh rekan-rekan mahasiswa dan para relawan (volunteer). Saat ini ada sekitar 51 relawan dan 7 orang pengurus inti termasuk Heardy (CEO Klinik Jalanan) yang tergabung dalam Klinik Jalanan Samarinda. Komunitas ini terbentuk dengan berlatar belakang kepedulian terhadap kondisi yang dialami dan sedang terjadi pada anak jalanan.

Progress in Social Development: Volume 1 No 2 Juli 2020 
Klinik ini berdiri secara resmi pada bulan Agustus 2015. Basecamp mereka beralamat di jalan K.H. Agus Salim Gang 2, Kota Samarinda.

Sekilas tampak Klinik Jalanan mengembangkan model-model pendekatan humanis yang lebih memanusiakan anak-anak jalanan. Tidak ada tanda-tanda model penangananan represif pada klinik ini, Anak jalanan nampak memiliki banyak kegiatan yang menyenanangkan. Tidak ada pakaian seragam atau kegiatankegiatan yang kaku dan formal, namun mereka tampak beraktivitas dengan gembira. Beberapa gejala ini membuat peneliti tertarik untuk melakukan observasi lebih lanjut dan rinci tentang strategi penguatan kapasitas (capacity building) anak jalanan di Klinik Jalanan Samarinda.

\section{METODE}

\subsection{Jenis Penelitian}

Penelitian ini menggunakan pendekatan observasi. Penelitian observasi ini dilakukan untuk menjajaki sebuah strategi atau model baru dalam menangani problema anak jalanan yang dilakukan oleh Klinik Jalanan Samarinda. Dalam penelitian observasi ini peneliti ingin menjelaskan hasil observasi terhadap strategi-strategi yang digunakan, tanpa harus menjelaskan atau membuktikan dengan teori.

\subsection{Profil Klinik Jalanan Samarinda}

Lokasi Sekertariat Klinik Jalanan Samarinda beralamat di jalan K.H. Agus Salim Gang 2, Kota Samarinda (rumah kontrakan). Sejarah perkembangannya, pada bulan Mei 2015 proyek sosial Klinik Jalanan memenangi sebuah acara Indonesian Culture and Nasionalism (ICN) yang diselenggarakan oleh Student Board S1 Prasetya Mulya School of Business and Economics di Kota Jakarta. Klinik Jalanan resmi berdiri pada bulan Agustus 2015 di Kota Samarinda. Visinya yaitu Sebagai suatu lembaga yang bergerak pada Proses Pencegahan, Pengobatan, dan Rehabilitasi anak jalanan pecandu inhalen (ngelem) dan pembinaan bagi anak-anak jalanan. Misinya yaitu pertama, Pusat Rehabilitasi, Pusat pendidikan, Pemberian Keterampilan, dan Tempat Pembinaan Anak Jalanan.

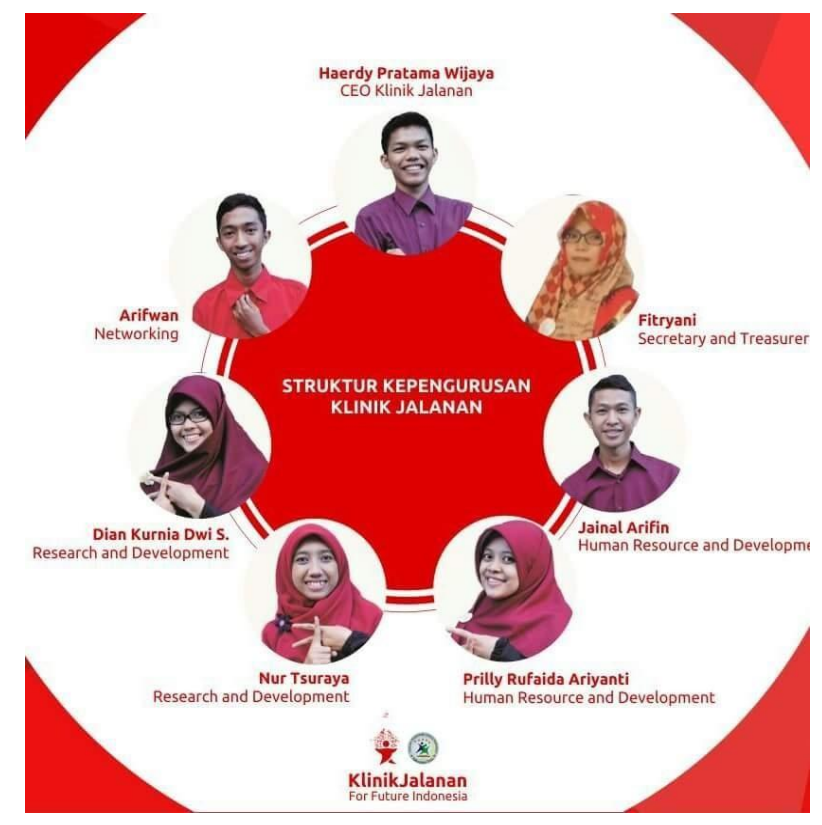

Figure 1. Facebook Klinik Jalanan 


\section{HASIL DAN PEMBAHASAN}

\subsection{Karakteristik Anak Jalanan Di Setiap Zona Pembinaan}

Pada tabel 5.1 dibawah ini, dapat dilihat secara ringkas mengenai karakteristik anak jalanan binaan Klinik Jalanan. Karakteristik tersebut dikelompokkan pada masing-masing zona pembinaan sebagai berikut:

Table 1. Karakteristik Anak Jalanan di Setiap Zona Pembinaan

\begin{tabular}{|c|c|c|c|c|}
\hline Zona & Tipe & Usia & Pendidkan & Masalah \\
\hline Pangeran Antasari & $\begin{array}{ll}\text { - } & \text { Dipekerjakan } \\
\text { - } & \text { Pergaulan yang } \\
\text { bebas (Sulit } \\
\text { dikondisikan) } \\
\text { - } \quad \text { lkut-ikutan Teman } \\
\text { Tinggal dengan } \\
\text { keluarga seperti } \\
\text { nenek, paman dan } \\
\text { tante } \\
\text { Berasal dari Sulawesi }\end{array}$ & $6-20$ & $\begin{array}{c}\text { Tidak } \\
\text { Sekolah }\end{array}$ & $\begin{array}{ll}- & \text { Ngelem } \\
- & \text { Buta Huruf }\end{array}$ \\
\hline Sempaja & $\begin{array}{l}\text { - } \\
\text { - } \\
\text { - } \\
\text { Memadah dikondisikan } \\
\text { Keluargantu Ekonomi } \\
\text { - } \quad \text { Tinggal dengan orang } \\
\text { tua (Orang asli } \\
\text { Samrinda }\end{array}$ & $10-14$ & $\begin{array}{l}\text { Sekolah } \\
\text { (SD, } \\
\text { SMP) }\end{array}$ & 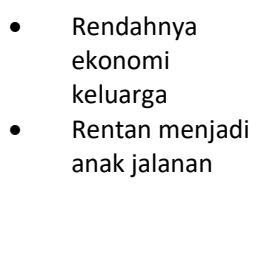 \\
\hline Lembuswana & $\begin{array}{ll}\text { - } & \text { Diepekrjakan } \\
\text { - } & \text { Pergaulan yang } \\
\text { bebas (Sulit } \\
\text { dikondisikan) } \\
\text { Tinggal dengan } \\
\text { keluarga seperti } \\
\text { nenek, paman dan } \\
\text { tante } \\
\text { - } \\
\text { Berasal dari Sulawesi }\end{array}$ & $6-18$ & $\begin{array}{l}1 \text { orang } \\
\text { sekolah } \\
(\mathrm{SMP}) \text {, } \\
\text { sisanya } \\
\text { tidak } \\
\text { sekolah }\end{array}$ & $\begin{array}{l}\text { - Penyalahgunaan } \\
\text { obat tramadol } \\
\text { - } \quad \text { Buta huruf }\end{array}$ \\
\hline Basuki Rahmat & $\begin{array}{ll}\text { - } & \text { Dipekerjakan } \\
\text { - } & \text { Pergaulan bebas } \\
\text { - } & \text { Tinggal dengan orang } \\
\text { tua } \\
\text { - } & \text { Beberapa anak } \\
\text { berasal dari Makassar } \\
\text { dan Ambon }\end{array}$ & $6-15$ & $\begin{array}{l}2 \text { orang } \\
\text { sekolah } \\
(\mathrm{SMP}) \text {, } \\
\text { sisanya } \\
\text { tidak } \\
\text { sekolah }\end{array}$ & $\begin{array}{ll}-\quad & \text { Ngelem } \\
\text { - } & \text { Buta Huruf }\end{array}$ \\
\hline
\end{tabular}

\subsection{Tiga (3) Aspek Strategi Di Klinik Jalanan}

Berdasarkan hasil penelitian dan observasi tentang strategi penguatan kapasitas (capacity building) terhadap anak jalanan di Klinik Jalanan Samarinda, maka disimpulkan bahwa dalam proses penguatan kapasitas anak jalanan yang dibina, Klinik Jalanan Samarinda berpegang pada tiga aspek yaitu; aspek rehabilitasi, aspek motivasi, dan aspek studi.

\subsubsection{Aspek Rehabilitasi}

Pada aspek rehabilitasi, relawan Klinik Jalanan menjelaskan kepada anak- anak jalanan yang kecanduan dan anak-anak jalanan lainnya tentang bahaya "ngelem" bagi kesehatan manusia. Dengan penjelasan secara langsung tentang bahaya-bahaya dari ngelem, relawan berharap anak-anak jalanan yang telah kecanduan ngelem, mengurangi jumlah konsumsi ngelem mereka. Mengurangi jumlah konsumsi ngelem maksudnya anak-anak jalanan pecandu lem yang biasanya ngelem 3 kaleng diusahakan tidak ngelem 3 kaleng lagi atau dikurangi. Penjelasan mengenai bahaya ngelem itu dilakukan oleh seluruh relawan sejak pembinaan awal, selama 1 bulan lebih di masing-masing zona pembinaan. Tujuannya agar anak-anak jalanan yang telah kecanduan ngelem dan anak-anak jalanan lainnya menjadi mengerti dan memahami bahaya ngelem bagi kesehatan mereka.

Sampai saat ini relawan Klinik Jalanan rutin menjaga dan mengawasi anak-anak jalanan binaannya jangan sampai ada yang kedapatan ngelem. Sedangkan yang dimaksud dengan istilah "Ngelem" adalah kegiatan 
menghirup aroma dari lem seperti lem fox dan lain sebagainya yang efeknya dapat membuat individu yang menghirup aroma dari lem tersebut menjadi teler atau mabuk.

Pada prosesnya, aspek rehabilitasi ini lebih intensif dan difokuskan di zona Basuki Rahmat dan zona Pangeran Antasari karena di dua zona tersebut anak-anak jalanannya adalah yang paling banyak ngelem. Parameter keberhasilannya, saat ini terlihat di zona Basuki Rahmat, anak-anak jalanan yang dibina sudah tidak ada yang ngelem. Sedangkan di zona Pangeran Antasari, anak- anak jalanan yang ngelem sudah berkurang, tidak sebanyak pada waktu Klinik Jalanan belum membina. Walaupun beberapa masih ada ditemui anak-anak jalanannya yang ngelem tapi jumlahnya tidak sebanyak dulu.

\subsubsection{Aspek Motivasi}

Pada prosesnya, setiap kali pembinaan, relawan selalu memberikan motivasi-motivasi dan semangat kepada anak-anak jalanan agar tetap ceria dan tetap semangat menjalani hidup meskipun kondisi mereka saat ini berada dibawah tekanan orang tua yang menyuruh mereka bekerja setiap hari di jalanan. Motivasi biasanya diberikan atau disisipkan lewat obrolan-obrolan santai. Lewat obrolan-obrolan tersebut relawan mensisipkan motivasi dan cerita-cerita yang menarik bagi anak-anak jalanan. Lewat obrolan itu juga anak-anak jalanan terpancing bercerita banyak kepada para relawan tentang apa yang mereka lakukan setiap hari dijalanan dan juga menceritakan kehidupan di keluarganya.

Di Klinik Jalanan, aspek motivasi ini sudah dimulai sejak tanda-tanda keakraban terjalin antara relawan dengan anak-anak jalanan. Tanda-tanda keakraban yang dimaksud adalah ketika anak-anak jalanan sudah tidak canggung lagi mengobrol dengan relawan. Dalam perjalanan pembinaannya selama lebih dari enam bulan, saat ini kedekatan antara para relawan dan anak-anak jalanan sudah sangat erat dan bahkan terlihat relawan sudah seperti kakak bagi anak-anak jalanan. Seringkali juuga peneliti melihat sebelum pembinaan akan dimulai, anakanak jalanan berlarian mendatangi para relawan di masing-masing zona pembinaan. Melalui motivasi dan sikap kepedulian yang dilakukan oleh seluruh relawan Klinik Jalanan, anak-anak jalanan merasa nyaman selama mengikuti program dan kegiatan - kegiatan pembinaan.

\subsubsection{Aspek Studi}

Aspek Studi di Klinik Jalanan berfokus pada pengembangan intelektual, emosional, dan spiritual anakanak jalanan.

a. Pengembangan Intelektual Anak Jalanan

Para relawan di Klinik Jalanan selain sebagai relawan juga berperan sebagai guru yang bertugas mengajarkan anak-anak jalanan menulis, membaca dan berhitung. Pengembangan intelektual anak jalanan bertujuan agar semua anak-anak jalanan yang dibina di klinik ini mampu menguasai dasardasasr menulis, membaca dan berhitung. Sebagian besar anak-anak jalanan yang dibina di klinik ini tidak sekolah dan buta huruf. Anak jalanan yang buta huruf jumlahnya paling banyak di zona Lembuswana karena mereka semuanya tidak ada yang sekolah. Untuk zona Sempaja, Pangeran Antasari, dan Basuki Rahmat beberapa anak jalanannya ada yang sekolah.

b. Pengembangan Emosional Anak Jalanan

Kehidupan sehari-hari di jalanan dapat mengubah atau membentuk kepribadian seseorang menjadi keras kepala, kasar, dan lain sebagainya akibat dari kondisi lingkungan jalanan. Begitu juga yang terjadi pada kepribadian anak-anak jalanan. Mereka cenderung hidup bebas tanpa aturan, seolah-olah mereka adalah penguasa di jalanan. Melalui aspek studi yaitu pengembangan emosional, Klinik Jalanan mencoba untuk memperbaiki perilaku anak-anak jalanan yang dibinanya. Relawan Klinik Jalanan berusaha mengubah tingkah laku anak- anak jalanan yang bertentangan dengan aturan/norma dan perilaku (moral) di masyarakat. Namun, untuk mengubah tingkah laku tidak baik anak-anak jalanan cukup sulit. Peneliti beberapa kali mengikuti pembinaan yang dilakukan para relawan Klinik Jalanan. Biasanya anak-anak jalanan mengeluarkan kata-kata mengumpat seperti "bangsat", "bodok", "anjing", "dasar goblok", dan berkata-kata kasar. Itu salah satu contoh tingkah laku anak-anak jalanan yang tidak baik. Terlihat, setiap kali pembinaan, relawan selalu berusaha mengubah tingkah laku anak-anak jalanan yang tidak baik itu dengan cara membujuk dan menasehati bahwa kata-kata umpatan itu tidak boleh/tidak baik.

c. Pengembangan Spiritual Anak Jalanan

Relawan Klinik Jalanan mengajarkan anak-anak jalanan membaca kitab suci (mengaji). Kegiatan mengaji ini rutin dilakukan pada jumat malam. Masing-masing relawan menjadi guru mengaji untuk anak-anak jalanan. Untuk ibadah seperti shalat terus di follow up. Selain itu juga untuk menggambarkan sisi spiritual kepada anak- anak jalanan, juga dikisahkan kisah-kisah teladan hidup, kisah-kisah para rasul dan lain sebagainya. 


\title{
4. KESIMPULAN (10 PT)
}

Berdasarkan hasil penelitian dan observasi tentang strategi penguatan kapasitas (capacity building) terhadap anak jalanan di Klinik Jalanan Samarinda, maka disimpulkan bahwa dalam proses penguatan kapasitas anak jalanan yang dibina, Klinik Jalanan Samarinda berpegang pada tiga aspek yaitu; aspek rehabilitasi, aspek motivasi, dan aspek studi. Keunggulan yang dimiliki Klinik Jalanan dilihat dari pendekatan awalnya yang mampu menciptakan suasana yang nyaman dan kekeluargaan bagi anak jalanan, para orang tua dan wali anak jalanan, mengajarkan anak-anak jalanan menulis dan membaca, membantu merehabilitasi anakanak jalanan pecandu ngelem dan menjadi fasilitator, serta konsisten melakukan pembinaan setiap 3 kali dalam seminggu. Kelemahan yang dimiliki Klinik Jalanan yaitu dalam hal Standar Operasional Prosedur atau (SOP) yang masih belum dilaksanakan dengan baik, penguatan relawannya, tempat/lokasi pembinaan, dan legalitas Klinik Jalanan masih belum jelas. Tantangan yang dihadapi Klinik Jalanan kedepan yaitu masih banyaknya anak - anak jalanan di Samarinda yang belum dibina Klinik Jalanan, pelatihan keterampilan kepada anak jalanan, dan pemberdayaan secara ekonomi bagi anak jalanan binaannya. Hambatan yang dihadapi Klinik Jalanan berasal dari internal dan eksternal Klinik Jalanan. Hambatan yang berasal dari internal Klinik Jalanan seperti manajemen waktu para relawan, keaktifan relawan, dan program-program pemberdayaan ekonomi yang belum terealisasi. Hambatan dari eksternal seperti kurangnya kesadaran orang tua terhadap bahaya aktivitas anak di jalanan, terkadang orang tua justru meminta anak untuk membantu mencari nafkah, dan kurangnya kesadaran masyarakat untuk tidak memberi atau melakukan pembelian/transaksi di jalanan.

\section{DAFTAR PUSTAKA}

G. Kartasapoetra, Hartini, 2007. KAMUS SOSIOLOGI DAN KEPENDUDUKAN,

PT. Bumi Aksara, Jakarta.

Soerjono Soekanto, 1985. KAMUS SOSIOLOGI, CV. Rajawali, Jakarta. Sugiyono, 2009. Metode Penelitian

Kuantitatif, Kualitatif dan $R \& D$, Alfabeta, Bandung.

Sugiyono, 2014. Memahami Penelitian Kualitatif, Alfabeta, Bandung.

Dokumen-dokumen:

Undang-Undang Republik Indonesia Nomor 35 Tahun 2014 Tentang Perubahan Atas UndangUndang Nomor 23 Tahun 2002 Tentang Perlindungan Anak.

\author{
Rujukan dari Jurnal dan Internet: \\ Jenivia Dwi Ratnasari, Mochamad Makmur, Heru Ribawanto. "PENGEMBANGAN \\ KAPASITAS (CAPACITY BUILDING) KELEMBAGAAN PADA BADAN \\ KEPEGAWAIAN DAERAH \\ KABUPATEN JOMBANG”. Jurnal Administrasi Publik (JAP), Vol.1, No.3, h. 103-110. \\ Universitas Brawijaya, Malang. \\ Tim Peneliti STIA LAN Makassar, 2012. "Capacity Building Birokrasi Pemerintah Daerah \\ Kabupaten/Kota di Indonesia”. http://iosrjournals.org/iosr-jbm/papers/Vol12- \\ issue1/A01210112.pdf?id=3529 (diakses 03 Desember 2015). \\ mutiara-fisip11. 23 Maret 2013. "Pengembangan Kapasitas Organisasi (Capacity Building)". Pengembangan \\ Kelembagaan, (Online), http://mutiara-fisip11.web.unair.ac.id/artikel_detail-75610- \\ Pengembangan $\% 20$ Kelembagaan- \\ Pengembangan\%20Kapasitas\%20Organisasi\%20(Capacity\%20Buildin g).html (diakses 30 \\ Oktober 2015). \\ http://e-journal.uajy.ac.id/1574/3/2EM16271.pdf (diakses 17 Desember 2015). http://skpm.ipb.ac.id/konsep- \\ komunitas-dan-masyarakat-dalam-perspektif- \\ sosiologi/ (diakses 17 Desember 2015) \\ http://digilib.unila.ac.id/11424/15/BAB\%20II.pdf (diakses 27 Januari 2016).
}

